\title{
ON THE ETIOLOGY AND TREATMENT OF PINK DISEASE
}

\author{
BY \\ J. VERNON BRAITHWAITE, M.D., M.R.C.P. \\ (From the Children's Hospital, Leicester Royal Infirmary.)
}

Pink disease, first described by Swift ${ }^{1}$ in Australia in 1914, was brought to the notice of the profession in this country by Thursfield, Paterson, and Greenfield $^{2,3}$ in 1922 and 1923. Since then a large number of cases have been reported and many excellent clinical descriptions have been given. Concerning the ætiology and treatment, however, there is still no certain knowledge, and different observers have reported conflicting results. The fact that most cases tend to recover slowly in hospital is no doubt partly the cause of this.

Incidence. - The disease appears to be getting more common, at any rate in the Midlands. Parsons ${ }^{4}$ in 1930 recorded an increasing incidence in Birmingham; whereas in 1920 only 2 cases were on record, there were 18 in 1929. The numbers admitted to the Children's Hospital of the Leicester Royal Infirmary since 1923 are shown in Chart I. Of the 27 cases on which this paper is based, 25 have occurred in the last four years.

CHART I.

Annual incidence in the Children's Hospital, Leicester.

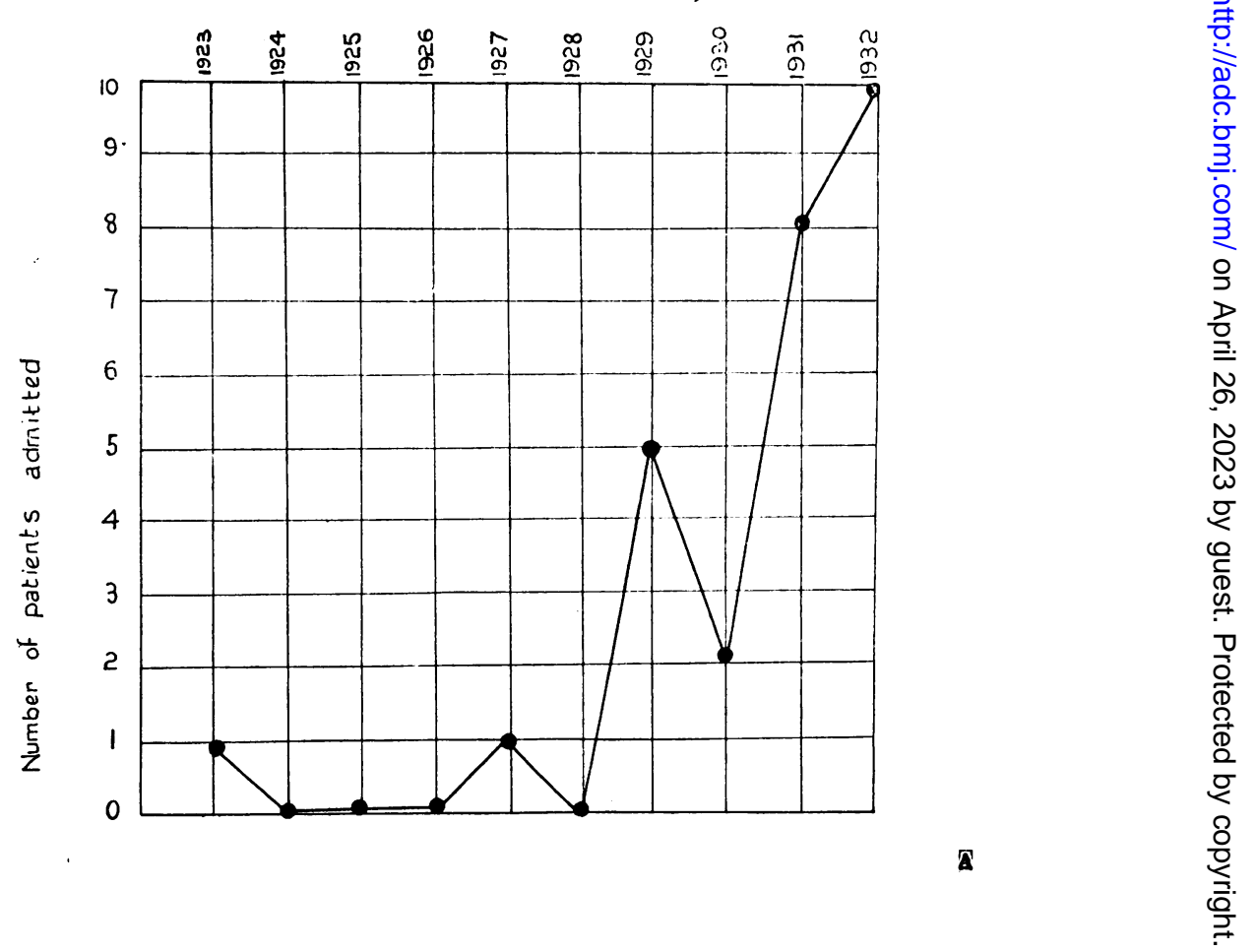


The great increase in the number of admissions during the last two years may be in part due to practitioners becoming familiar with the disease.

Symptoms.-The symptoms and signs of pink disease are now so well known that a detailed account of them is unnecessary. The cardinal symptoms are erythrœedema, a polymorphic rash followed by desquamation, marked anorexia, muscular hypotonia, mental depression, photophobia, and sweating. The condition can be diagnosed at a glance. One sign has been constantly observed in this series which is not mentioned elsewhere, namely, the rapid eruption of teeth. Falling out of the teeth, which is said to be most typical of the disease, only occurred in one of these patients, and alopecia was not marked. In other ways the symptomatology in the present series of cases agreed closely with that given in the literature.

\section{Etiological factors.}

Sex.-Most observers record a preponderance of males. In this series the sexes were equal, 14 girls and 13 boys.

Age at onset.-This is difficult to ascertain with accuracy, as the onset is so insidious. Vague symptoms of nasal catarrh gradually develop into the complete clinical picture. As far as could be determined the age at onset varied from 4 to 22 months, averaging 9 months.

Diet.-This in our cases was always good. Eighteen patients had been wholly or partially breast fed, and the diet of the others was well supplied with vitamins.

Geographical distribution.-The disease was first described in Australia, and cases have since been reported from America, New Zealand, and Switzerland, as well as from this country. It should be noted that the cases from abroad have all occurred in particularly sunny countries.

When the local geographical distribution is considered it is seen that pink disease is an illness of rural rather than of urban districts. Twenty of the 27 cases under consideration (74 per cent.) came from suburban or country homes; whereas of the last 500 children admitted into the Children's Hospital only 58 per cent. came from the suburbs or country.

Number in family.-Eight out of 22 of these patients were only children. The average number of children in the family was 2.7 .

It is concluded, therefore, that pink disease occurs chiefly in well caredfor children in good surroundings.

Seasonal incidence.-Previous accounts do not show any marked seasonal variations. The majority of these cases were admitted either in the early summer or autumn, while only 4 were admitted between the months of October and March. If the cases reported by Paterson and Greenfield ${ }^{3}$, and Wyllie and Stern ${ }^{10}$ (in which the date of admission is given) are added 
to our own, making a series of 39 patients from this country, the biennial rise becomes more pronounced. The maximum number of admissions is in August. It is fully realized that there is usually history of one or two months' illness before the child is admitted, but it is at this time that the child becomes so much worse that hospital treatment is sought. It is suggested that the vernal rise is due to recent prevalence of acute respiratory catarrh, and that the autumnal increase is due to the continued effect of increased daylight.

CHART II.

Seasonal incidence.

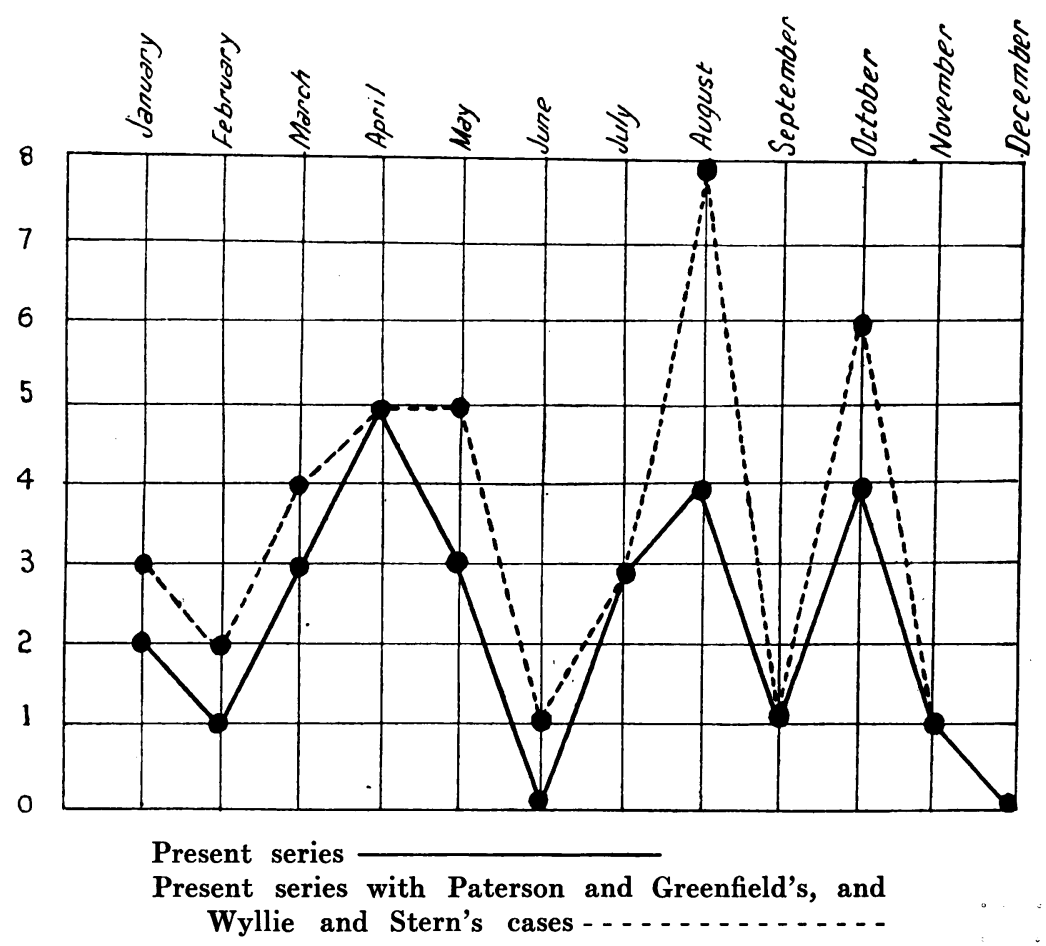

Prodromal infections.-Some form of acute respiratory catarrh invariably precedes or accompanies the onset of the disease. Byfield ${ }^{5}$ in his classical account found respiratory infection constantly present. In 12 of the cases of the present series the mother definitely attributed the illness to a severe cold; in 1 patient it followed tonsillitis, in 1 measles, and in 1 bronchopneumonia. Running of the eyes and nose was invariably present.

Summary of ætiological factors.-The foregoing facts suggest that pink disease is due to an abnormal reaction to daylight in a child that has recently suffered from an acute infection of the respiratory tract.

In this connexion it is interesting to note the experiments of L. J. Harris ${ }^{6}$ on hypervitaminosis $D$ in the rat. It was found that a moderate excess of vitamin D produces a greatly increased net absorption of calcium and 
phosphorus, a tendency to hypercalcæmia and hyperphosphatæmia, and excessive formation of densely calcified new bone. Similar changes occur in the teeth, the cement becoming over-calcified and a remarkable overgrowth of cementoid forming, which may become ankylosed to the alveolar bone; abnormal new deposits of dentine are also laid down; lime salts are extensively deposited in the soft tissues. If maximal toxic doses of the vitamin are given, however, the animal becomes very ill with loss of appetite and a breakdown in the gut function, and the changes described as the result of increased calcium absorption are not observed. In children Hess and Lewis ${ }^{7}$ had obtained very similar results. They found that irradiated ergosterol in doses of 2.5-5 mgrm. not only cured rickets, but caused hypercalcæmia and hyperphosphatæmia. Beyond causing eburnation of the healed bones, this was not associated with any marked clinical effects. In 2 of their cases, however, the excess of blood calcium was accompanied by curious symptoms. There was moderate fever, marked drowsiness, and a peculiar mental condition. The electrical reactions were found to be sluggish. Albumin and casts appeared in the urine. Although the blood calcium rose considerably, the phosphorus remained normal. All these symptoms and signs have been repeatedly observed in pink disease.

\section{The blood in pink disease.}

Blood calcium and phosphorus.-Acting on the above hypothesis, that pink disease is essentially an abnormal reaction to light in an infected child, it was decided to estimate the blood calcium in patients suffering from this illness. This was done in 18 cases, and the plasma phosphorus was estimated in 4 cases. The results are given in Table 1.

TABLE 1.

Calcium and phosphorus estimations in pink disease.

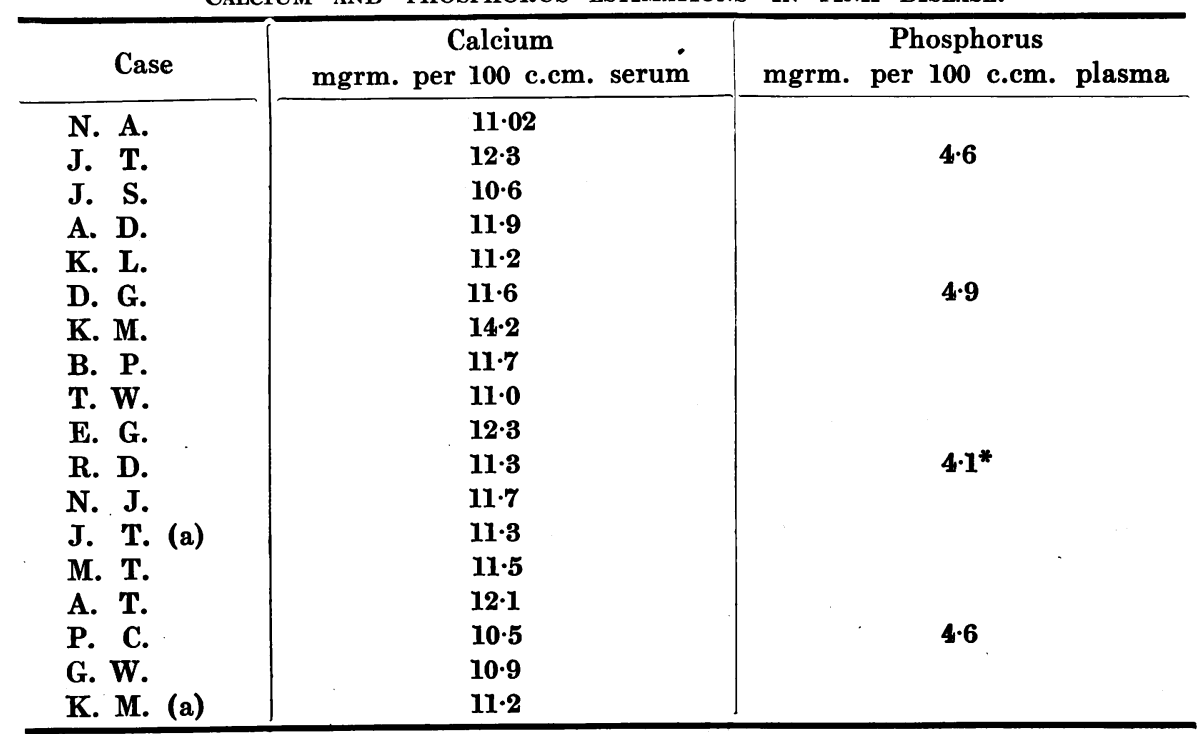

* After treatment by intraperitoneal citrate. 
It will be seen from Table 1 that the blood calcium is slightly but definitely raised in most cases. This may well be the cause of some of the symptoms, e.g., muscular hypotonia, mental depression, and the rapid cutting of teeth. In the cases in which the phosphorus was estimated this does not show any corresponding rise. These results are similar to those obtained by Hess and Lewis $^{7}$ in hypervitaminosis $\mathbf{D}$.

Blood counts.-The cellular elements of the blood were found to be almost constantly increased. Previous observers have recorded the constant occurrence of leucocytosis. In my experience a marked increase in the number of red blood cells and a rise in the percentage of hæmoglobin were almost equally constant (Table 2). It is suggested that the degree of leucocytosis is dependent on the activity of the respiratory infection.

TABLE 2.

Blood Counts in PINK Disease.

\begin{tabular}{|c|c|c|c|c|}
\hline Case & Red cell count & $\begin{array}{c}\text { Percentage of } \\
\text { hæmoglobin }\end{array}$ & White cell count & $\begin{array}{l}\text { Percentage of } \\
\text { polymorph. cells }\end{array}$ \\
\hline N. A. & $5,250,000$ & 98 & 13,000 & 34 \\
\hline J. T. & $5,600,000$ & $11^{\prime} 0$ & 16,000 & 64 \\
\hline J. S. & $6,166,000$ & 93 & 7,187 & 21 \\
\hline A. D. & $6,066,640$ & 102 & 10,937 & 48 \\
\hline K. L. & $4,420,000$ & 75 & 14,000 & 53 \\
\hline D. G. & $4,833,000$ & 70 & 18,437 & 64 \\
\hline K. M. & $6,800,000$ & 97 & 15,000 & 80 \\
\hline B. P. & $5,633,000$ & 89 & 9,687 & 41 \\
\hline T. W. & $5,466,000$ & 92 & 13,437 & 60 \\
\hline E. G. & $6,133,000$ & 100 & 10,396 & 36 \\
\hline R. D. & $5,502,000$ & $8 \dot{5}$ & 23,437 & 68 \\
\hline N. J. & $4,634,000$ & 93 & 8,432 & 49 \\
\hline J. T. (a) & $5,716,000$ & 103 & 9,060 & 44 \\
\hline N. T. & $6,606,000$ & 120 & 28,124 & 29 \\
\hline A. $\mathbf{T}$. & $5,450,000$ & 100 & 20,937 & 32 \\
\hline P. C. & $6,017,000$ & 90 & 14,062 & 73 \\
\hline G. W. & $6,416,000$ & 110 & 19,062 & 46 \\
\hline K. M. (a) & $5,833,000$ & 100 & 9,375 & \\
\hline
\end{tabular}

It is seen that the increase in the amount of hæmoglobin is not always in proportion with the increase in red cells. The leucocytosis is very variable, and there is only an occasional increase in the percentage of polymorphonuclear cells.

Sedimentation rate.-This was estimated in 11 patients with very varied results (Table 3). Six showed a very rapid sedimentation rate; 4 of these had over 100 per cent. hæmoglobin. On the other hand 2 patients each had 100 per cent. hæmoglobin but no increase in sedimentation rate. A rapid sedimentation is usually held to indicate a high serum protein, but it is conceivable that it may be due to smallness of the red cells with a normal or increased specific gravity. Further work is required in this and other 
directions concerning the physics and chemistry of the blood in pink disease. It may be mentioned, however, that halometric readings suggest that the red cells are small in this affection.

TABLE 3.

\begin{tabular}{lccccc} 
Case & & & & \multicolumn{2}{c}{$\begin{array}{c}\text { Sedimentation rate } \\
\text { (mm. per hour) }\end{array}$} \\
J. T. & $\ldots$ & $\ldots$ & $\ldots$ & $\ldots$ & $\mathbf{1 6 \cdot 2 5}$ \\
A. D. & $\ldots$ & $\ldots$ & $\ldots$ & $\ldots$ & $\mathbf{1 6 \cdot 2 5}$ \\
D. G. & $\ldots$ & $\ldots$ & $\ldots$ & $\ldots$ & $\mathbf{1 1 \cdot 2 5}$ \\
B. P. & $\ldots$ & $\ldots$ & $\ldots$ & $\ldots$ & $\mathbf{1} \cdot 125$ \\
E. G. & $\ldots$ & $\ldots$ & $\ldots$ & $\ldots$ & $\mathbf{3} \cdot 75$ \\
R. D. & $\ldots$ & $\ldots$ & $\ldots$ & $\ldots$ & $\mathbf{4} \cdot 875$ \\
N. J. & $\ldots$ & $\ldots$ & $\ldots$ & $\ldots$ & $\mathbf{1 3 \cdot 0}$ \\
J. T. (a) & $\ldots$ & $\ldots$ & $\ldots$ & $\ldots$ & $\mathbf{1 6 \cdot 2 5}$ \\
M. T. & $\ldots$ & $\ldots$ & $\ldots$ & $\ldots$ & $\mathbf{2 1 \cdot 5}$ \\
P. C. & $\ldots$ & $\ldots$ & $\ldots$ & $\ldots$ & $\mathbf{4 \cdot 7 5}$ \\
K. M. (a) & $\ldots$ & $\ldots$ & $\ldots$ & $\ldots$ & $\mathbf{5 \cdot 2 5}$ \\
& & \multicolumn{2}{l}{ Treatment. } & &
\end{tabular}

Pink disease as a rule tends to recovery in hospital. It is my belief that this is due to the fact that the patients are kept indoors there, usually in the middle of a large city, and are thus protected from many of the rays of normal sunlight. But whatever the reason, it has led to several conflicting claims for specific treatment.

Many of the manifestations of the malady suggest a deficiency disease allied to beri-beri or pellagra. There is a good deal of evidence against such an hypothesis: e.g., the varied diet of the great majority of the patients, the high percentage of breast-fed babies of normal mothers, and the occurrence of pink disease in England where vitamin-B deficiency, at any rate to severe degree, is uncommon. Nevertheless, treatment by a diet rich in vitamin $B$ is popular, and good results have been reported from it.

In 1927 Boas $^{8}$ produced a curious deficiency disease in young rats by feeding them on a diet adequate in every respect save that the sole source of protein was dried egg-white. The egg-white had to be dessicated before symptoms could be produced, and coagulation by boiling previous to dessication destroyed its harmful effect. Potato starch, egg yolk, and milk among many other substances, protected the animals. The affected rats developed a skin eruption, alopecia, blepharitis, a musty smell and loss of weight. Later they showed skin hæmorrhages and spasticity, and assumed a crouching attitude. Marshall Findlay and Stern ${ }^{9}$ repeated the experiments of Boas and confirmed her results. They also found that the disease could be produced in suckling rats by feeding the mothers on a deficient diet. In their opinion this syndrome in the rat is the equivalent of pink disease in children. The terminal symptoms of purpura, and spasticity are very different from anything observed in pink disease, but there was a certain amount of support for their hypothesis from post-mortem appearances. The most striking thing about their work was their discovery that raw liver caused all symptoms to disappear rapidly. In 1981 Wyllie and Stern ${ }^{10}$ 
published the results of feeding 5 patients suffering from pink disease with raw liver. Four of the 5 did well, being practically cured in from 1 to 6 weeks. The remaining child was treated for 3 months at home, but he showed no improvement until he was taken into hospital, when he recovered in a fortnight.

Bruton Sweet ${ }^{11}$ treated 17 patients with ultra-violet light from a mercury-vapour lamp. He found that when treatment was given at threeday intervals the condition was relieved in about 4 weeks.

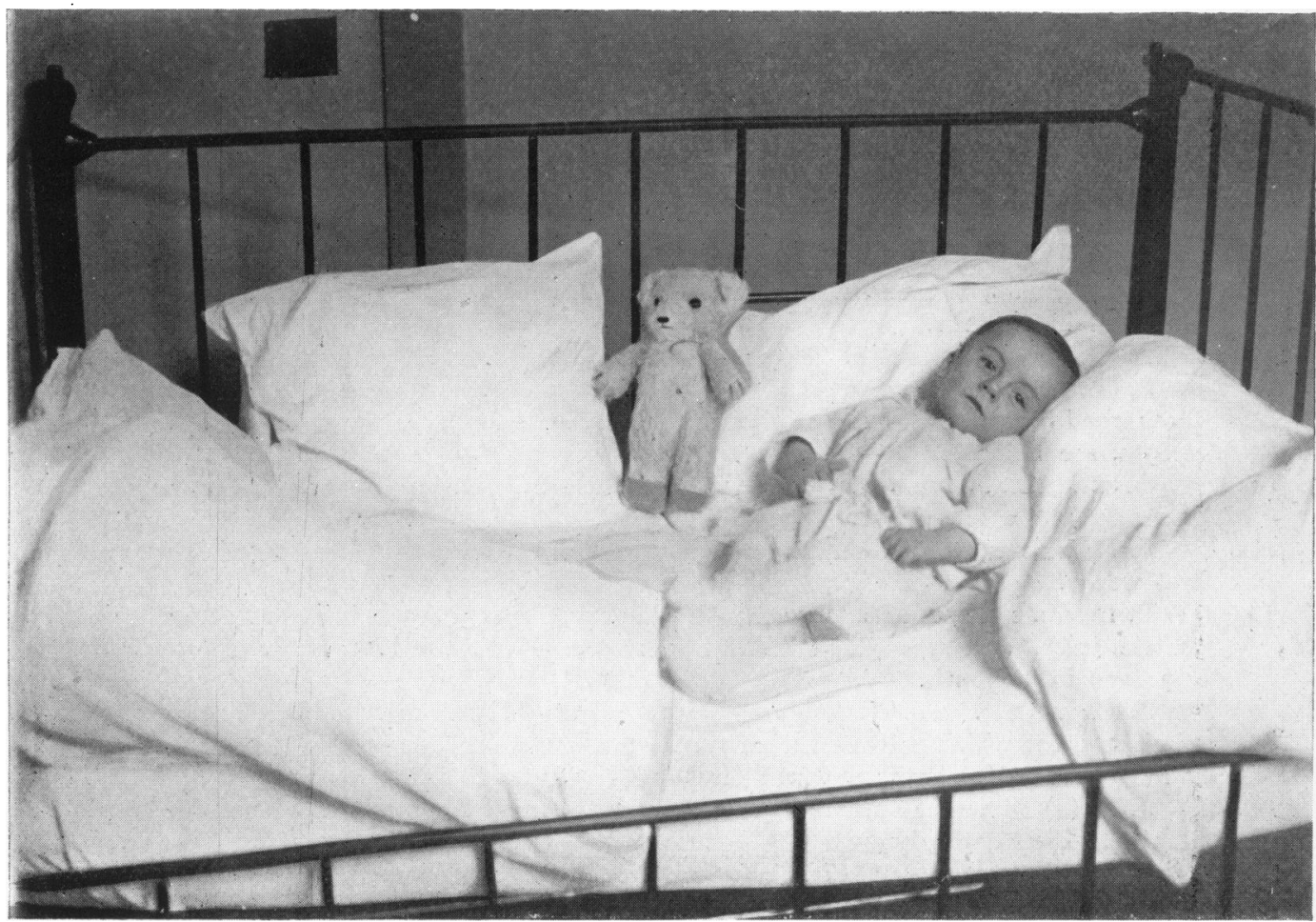

FIG. 1.-Showing the arrangement of the cot.

General measures.-In the treatment of the present series it was found that the patients were more comfortable if they were allowed to assume any position they liked on the bed, uncovered by bed-clothes. They were kept warm by wearing woolly suits which could not be removed by the patient, both hands and feet covered. The sides of the cots had to be protected by numerous pillows (Fig. 1), otherwise the children, especially when they began to recover, tried to sit up and then fell over and hurt themselves on the bars. Great pains were taken by the nursing staff to try to get the children to eat, as increase in amount of food taken and general improvement invariably occur simultaneously. 
Specific treatment.-Eleven patients had no special treatment given save that some had massage; 2 were given thyroid extract, and 1 was given hydrochloric acid before food. These were used as controls in estimating the effect of other methods of treatment. Five were given liver, and 3 of them had a vitamin-B food (Bemax) in addition. Five patients were treated by ultra-violet light from a carbon arc lamp or vitamins $\mathbf{A}$ and $\mathbf{D}$.

Three children were given intravenous or intraperitoneal sodium citrate with a view to bringing down the level of blood calcium. Two others were also given this treatment, but it was combined with keeping them in a room the windows of which were glazed with ruby glass, so that they were kept free from exposure to any rays from the violet end of the spectrum. Three patients received no treatment other than being kept in the red windowed room.

Control Patients. - The details of the cases used as controls were as follows :-

I. S., female, 14 months. One month's history. Massage; thyroid extract. Much improved in 6 weeks.

B. G., female, 8 months. Three months' history. Died a few days after admission.

L. Y., female, 10 months. Four months' history. Massage; thyroid extract. Discharged in 6 weeks apparently cured. Relapse 2 months later. (For treatment of relapse, see below.)

L. B., male, 17 months. One month's history. Owing to ward infection was discharged in a fortnight unchanged.

J. I., female, 26 months. Four months' history. Massage. Discharged improved in 6 weeks.

P. B., male, 12 months. One month's history. Was found to have low chlorides in gastric juice, and was given Acid. hydrochlor. dil., $10 \mathrm{~min}$. t. d. s. Discharged improved in 1 month.

J. C., male, 10 months. Two months' history. Developed mumps 2 days after admission, for which he was discharged for 2 months. After readmission he remained in hospital for $2 \frac{1}{2}$ months and was discharged very much improved.

J. T. (a), female, 10 months. Five months' history. No treatment beyond general nursing. Discharged improved in 6 weeks.

A. T., female, 10 months. Two months' history. Massage. Discharged much improved in 6 weeks.

T. W., male, 12 months. Four months' history. Died 3 days after admission. Post-mortem not obtained.

A. C., male, 9 months. Four months' history. Died five days later. Post-mortem nothing abnormal save congestion of lungs and spleen and fatty infiltration of liver; horny layer of skin thickened.

The fatal cases all had a long history and were admitted moribund. The other patients usually recovered sufficiently to be discharged in about 6 weeks.

Patients treated with vitamin B and liver.-Five cases fall into this group:-

N. A., female, 15 months. Four months' history. Bemax 3 weeks, ? slight improvement. Malted liver given, after which patient became definitely worse. Treatment persisted in for a fortnight during which time she had persistent diarrhoea. Condition of child made it advisable to stop treatment. Bemax again given, followed by gradual improvement. Fit for discharge 3 months after admission, 
J. S., male, 7 months. One month's history. Malted liver. Discharged by request in 3 weeks, slightly improved.

A. D., male, 6 months. One month's history. Diarrhœa on admission for which dietetic treatment (acid milk with casein, with malt added later) was given with satisfactory results in 18 days. The $\frac{1}{2}$-oz. of raw liver ground up with port wine was given daily. Patient became ill with diarrhœa and treatment had to be abandoned. For further treatment see below.

K. L., female, 24 months. Three months' history. Bemax and raw liver. Was improving slowly in 2 months, but had to be discharged owing to measles in the ward.

K. M., 13 months. One month's history. Acid hydrochlor. dil., 5 min. t. d. s., tried for 3 weeks without improvement. Bemax and cod-liver-oil and malt then given. Slow improvement, but patient still ill after three months. Raw liver then given for a week. Patient lost appetite, vomited, developed diarrhœa, and became odematous round the eyelids; lost all weight previously gained. Liver stopped, and Bemax and cod-liver-oil started again. Gradually improved, and was well enough for discharge $5 \frac{1}{2}$ months after admission.

From these 5 cases, 2 of which were treated by liver alone, and 3 by liver combined with Bemax, it appears that vitamin B has no marked effect, but that liver may be definitely harmful. It is not easy to explain the exactly opposite results obtained by Wyllie and Stern. Possibly their patients were benefited very considerably by being taken into hospital-one of them failing to show any improvement while treatment was being given at home, but immediately improving on being admitted. In Leicester the children's ward is modern, being particularly light and airy. It is conceivable that in the older and more venerable institutions of the metropolis the patients were not exposed to active daylight rays to the same extent.

Treatment By ultra-violet light and vitamins A and D.-The following are the details of the cases in this group :-

L. Y. After readmission for relapse slow improvement took place with U.V.L. Discharged very much improved in 3 months.

D. G., male, 12 months. Two months' history. U.V.L. Discharged improved in 6 weeks. Blood calcium, 13.10.31. $=11 \cdot 6 ; 25.11 .31 .=11 \cdot 9$.

B. P., male, 12 months. Three months' history. Was improving on 'admission. U.V.L. 6 treatments. Was discharged in a fortnight very much improved. Blood calcium, 14.6.32. $=11 \cdot 7 ; 27.6 .32 .=11 \cdot 5$.

J. T., female, 11 months. Five months' history. Radiostoleum for 3 months. No change.

K. M. In addition to treatment by liver and Bemax this patient had cod-liver-oil and malt, with no marked effect.

This treatment did not have much effect on the course of the disease. It is interesting to note that ultra-violet light did not alter the amount of calcium in the blood. Certainly the treatment did no harm. This may be due to the fact that both the carbon-arc and mercury-vapour lamps do not give off the short wave rays which may be the harmful ones. The improvement noted by Bruton Sweet ${ }^{11}$, and suggested in 2 of the present series, may be due to a vaccine-like action, and gradually increasing doses producing immunity. 
Treatment by citrate injections and Red-windowed room.-(a) A group of cases received treatment by citrate injections only. The details were as follows:-

J. T. After this patient had been in hospital 3 months without improvement, half an ounce of a 3.5 per cent. solution of sodium citrate was injected intravenously. Within half an hour the child became much brighter in herself, but this immediate

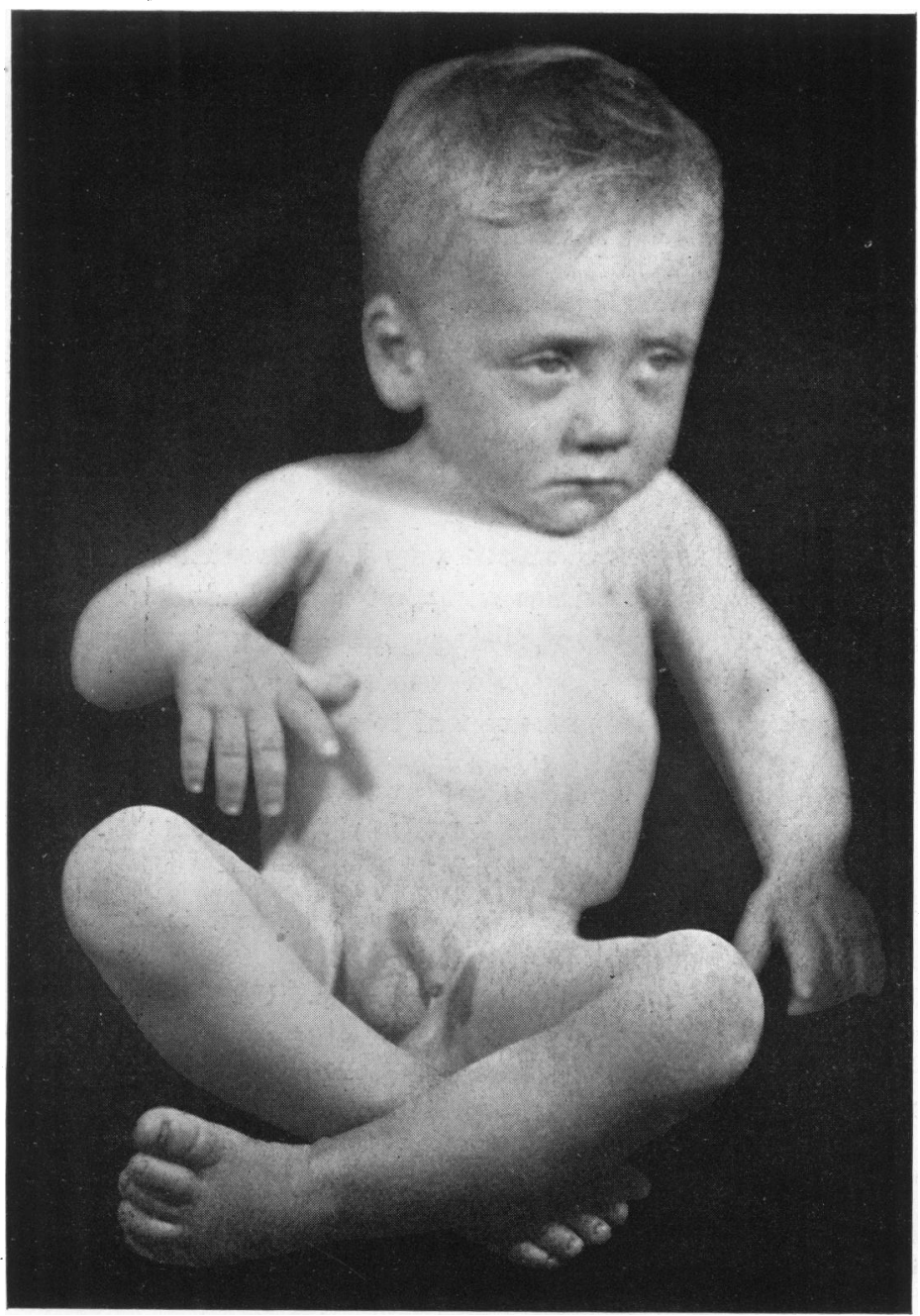

Fig. 2.-N. J., before treatment.

reaction only lasted a day or two, and the patient became atonic and unhappy again. However, steady, if slow, improvement set in, and although she had an attack of infective diarrhœa a month later, she was discharged 2 months after the citrate injection with convalescence well established.

A. D. When this patient had recovered from the effect of the liver (about a week after discontinuing it) $15 \mathrm{c.cm}$. of 3.5 per cent. sodium citrate solution and $10 \mathrm{c} . \mathrm{cm}$. of normal saline were injected intraperitoneally. Immediately before the 
injection, the blood calcium was $11.9 \mathrm{mgrm}$. per $100 \mathrm{c.cm}$. serum. The injection was repeated on the following day. Twenty-four hours later the child had definitely improved, the blood calcium being 10.9. Thereafter there was a steady gain in weight and improvement in general health, and the patient was discharged a month later doing well.

E. G., female, 6 months. One month's history. Blood calcium on admission was $12 \cdot 3 \mathrm{mgrm}$. per $100 \mathrm{c.cm}$. serum. A week later $10 \mathrm{c.cm}$. of a 4 per cent. sodium citrate solution were injected intraperitoneally. On the following day the blood

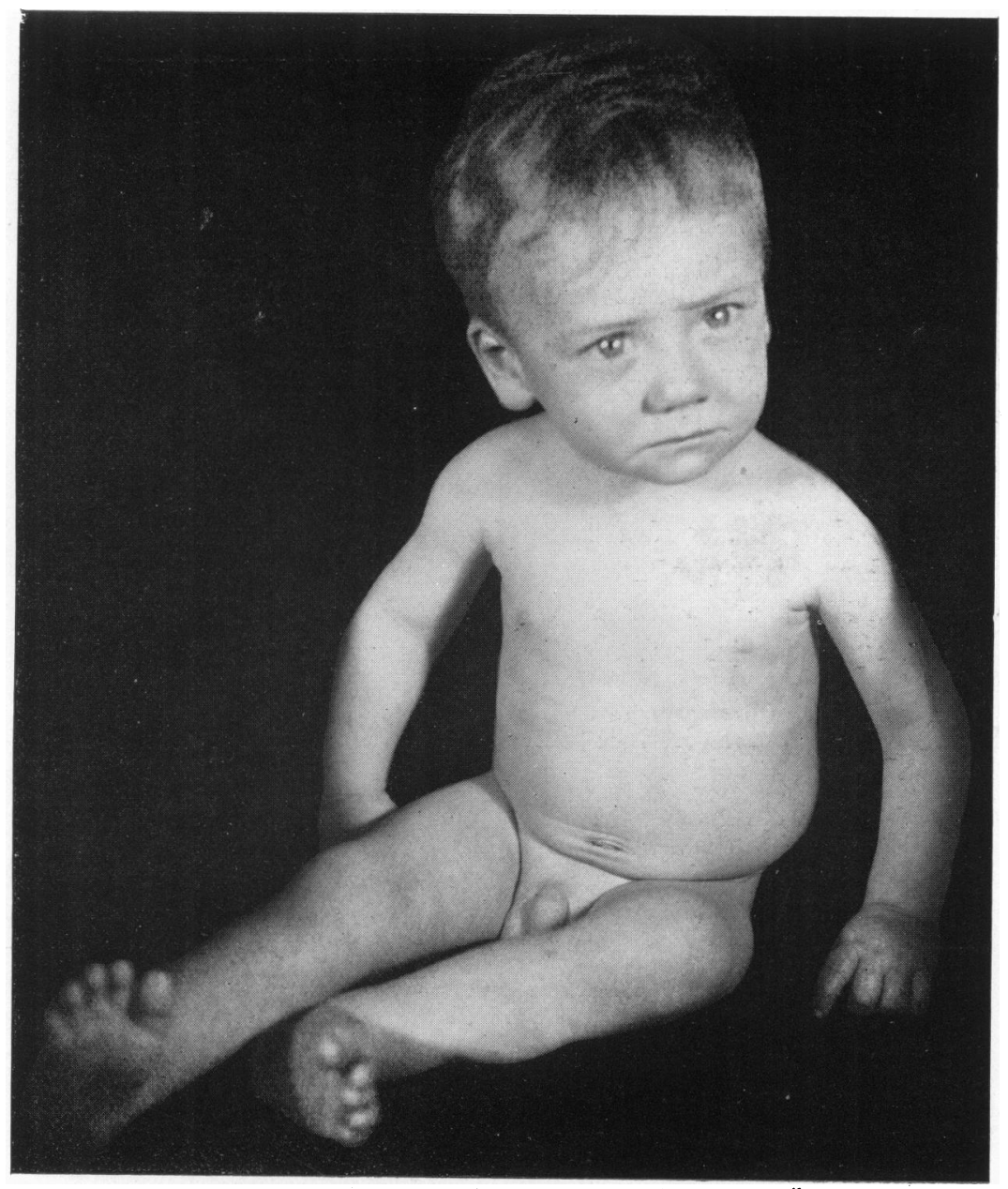

Fig. 3.-N. J., after treatment.

calcium was 10.4. The child improved rapidly in a week, sat up, and began to take food. The pink colour began to fade from the hands. Then the condition relapsed, and on the third day of the relapse a further injection of citrate was administered. The child again improved rapidly, and was discharged apparently well 6 weeks after admission.

R. D., male, 8 months. One month's history. 23.3.32. Blood calcium $=11 \cdot 3 \mathrm{mgrm}$. 10 c.cm. 4 per cent. sodium citrate solution given intraperitoneally. Blood calcium after injection 10.5. By 25th was definitely better, and by 28 th was able to stand. 
On 31st the injection was repeated. Thereafter the child made a rapid recovery and was discharged apparently cured 7 weeks after admission.

From these 4 cases it appears that the injection of sodium citrate had an immediate beneficial effect on the patients, and that the blood calcium was lowered. The immediate effect wore off in a day or two, but steady improvement set in, although it cannot be claimed that the children's stay in hospital was much shortened.

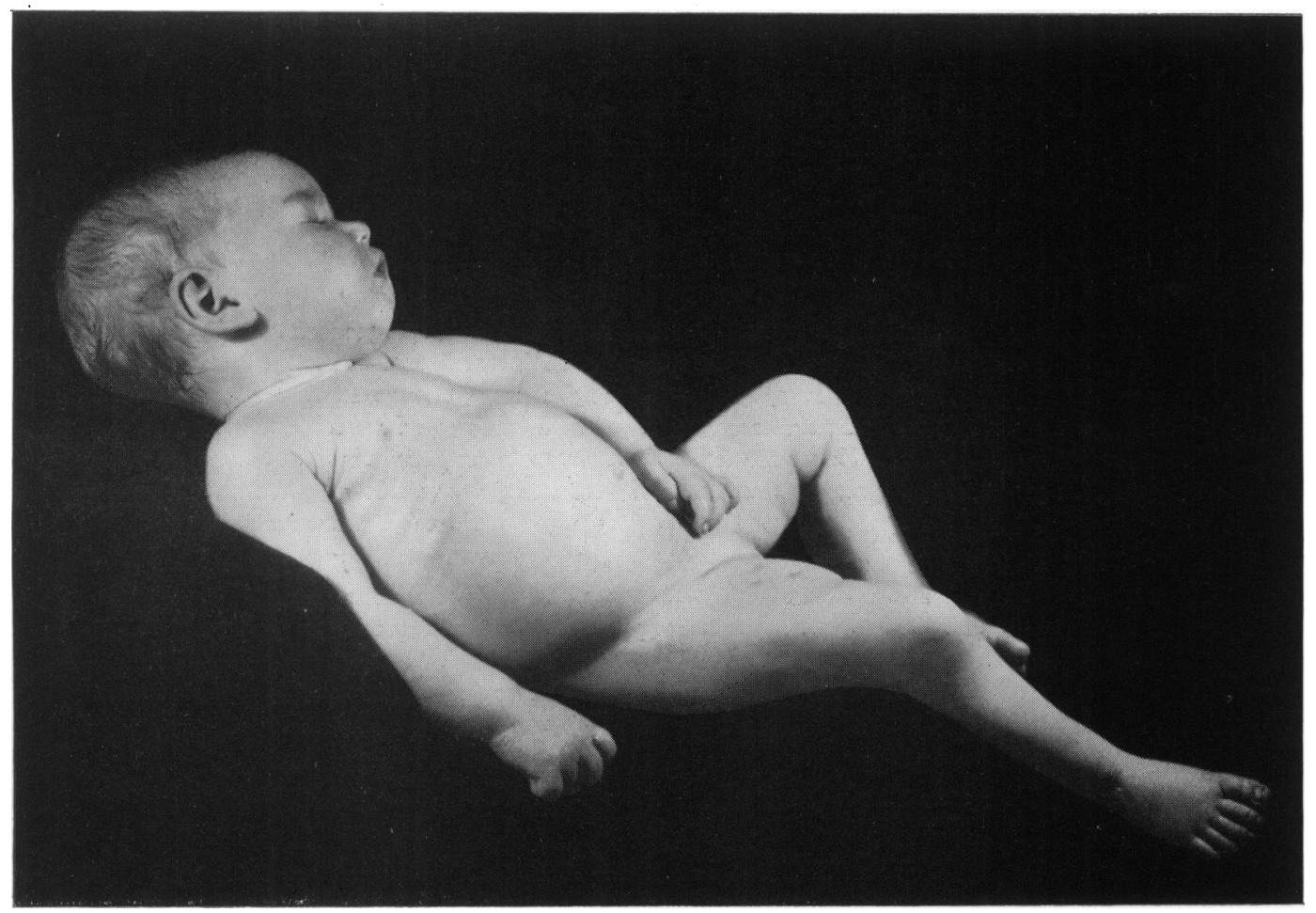

FIG. 4.-M. T., before treatment.

(b) Two children received treatment by citrate injections combined with the red-windowed room:-

N. J., male, 12 months. Two months' history. On April 28th his blood calcium was $11.7 \mathrm{mgrm}$. On May 6th 20 c.cm. 4 per cent. sodium citrate injected intraperitoneally. Two days later he was sitting up and holding up head, and was less pink about nose and hands. On May 9th he was not so well and was very limp sagain. Injection repeated, but no marked improvement followed. On May 23rd his blood calcium was 11.8. On 29th he was put into the red room. The child seemed unhappy for the first 24 hours, apparently missing the company of the other patients, but he took feeds well. In two days the muscle tone appeared normal, the child was sitting up and feeding well. Improvement maintained until June 6th when the blood calcium was 10.6. On this date owing to the ward being cleaned the patient had to be removed from the red room to a temporary ward. As there was an openair balcony in this ward the experiment was cautiously made of putting the child in the sun (June 9). Within an hour the patient showed signs of great discomfort, 
cyanosis, and collapse, and was at once removed into the ward where he gradually recovered. In 2 days the patient was able to go back to the red room, and 3 days later-a fortnight after his first going there-he appeared quite normal (Fig. 1 and 2).

This patient developed a small abscess in the leg, and on account of this remained in hospital for a further 3 weeks. The abscess cleared up normally after incision. He was seen at out-patients some weeks later and appeared perfectly well.

M. T., female, 6 months. Two month' history. For the first 3 weeks after admission there was no change. Blood calcium $=11.5 \mathrm{mgrm}$. On May 2nd, 1932,

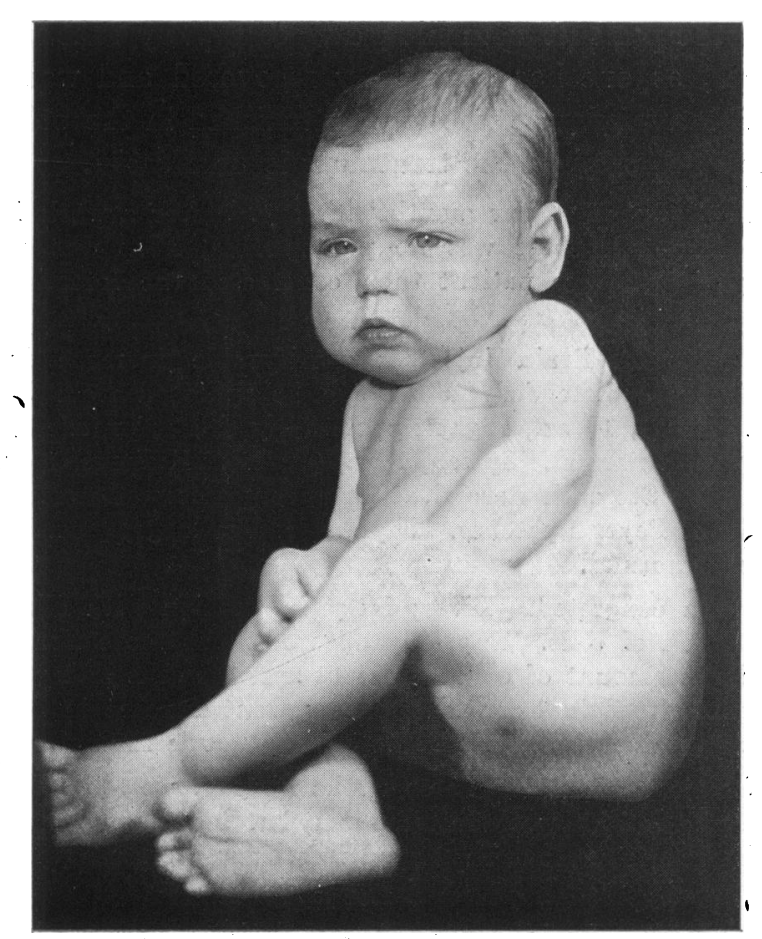

Fig. 5.-M. T., after treatment.

20 c.cm. 4 per cent. sodium citrate solution was injected intraperitoneally. No marked improvement. The injection was repeated on May 6th. Slow improvement started. Twelve days later the patient was smiling and taking feeds better. On May 21st the injection was repeated, and the next day she was not so well. On May 23rd her blood calcium was 12.5. On May 29th she was put into red room and was at first miserable and crying. By June 2nd there was definite improvement in muscle tone and mental condition. On the 5 th she was removed from red room to temporary ward, owing to ward cleansing. Improvement was maintained, but blood calcium still 12.3. On June 11th she returned to the red room. Not so peevish this time. Rapid improvement set in, and on June 24th she was discharged feeding well,

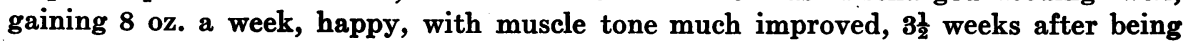
put into red room (Fig. 3 and 4). Seen at outpatients some weeks later, she was apparently normal.

Both these patients showed very marked improvement after being in the red-windowed room for 2 or 3 days. They did not respond to the citrate 
treatment as well as the other patients had done. It is interesting that in one of them the blood calcium remained high, although the clinical symptoms had practically disappeared; and that in the other, exposure to sunlight had an alarming effect.

(c) Three patients received treatment by red-windowed room only. Unfortunately 2 out of these 3 patients contracted infectious diarrhœa and died. There was a mild ward epidemic, and although in the other children who suffered from the infection it produced only a trifling disturbance for a few days, both the patients with pink disease rapidly succumbed within 12 hours. However, as one has apparently recovered and was waiting to be discharged, and convalescence was well established in the other, their value as evidence of the efficacy of the treatment is unaffected.

P. C., male, 10 months. Four months' history. After a week in the red room sweating had disappeared, there was no photophobia, sleep was normal, and the appetite was improving. The patient then contracted the infection and died the same night.

Post-mortem report. Brain injected; considerable increase in cerebro-spinal fluid, but ventricles not distended. Fluid can be squeezed from both lungs, main bronchi injected. Heart, $1 \frac{1}{2}$ oz., slight hypertrophy of left ventricle; valves normal. Liver, 12 oz., appeared normal. Spleen, 1 oz., normal. Kidneys, 1 oz. each, normal. Suprarenals normal. Stomach normal. Some congestion of mucosa of ileum and colon with atrophy of Peyer's patches. Thymus, rather large, $\frac{1}{2}$ oz. Thyroid normal. Spinal cord appears normal.

Sections. Spleen congested. Liver; fatty infiltration with dilated bloodvessels and some degeneration of cells. Thyroid appeared much more fibrous than normal, but there was a large amount of colloid present and the cells lining the acini appear normal. Brain normal. Spinal cord showed apparent increase in the neuroglia cells of the white matter, otherwise normal. Voluntary muscle normal.

K. M. (a), female, 7 months. Three weeks history. Blood calcium $11 \cdot 2 \mathrm{mgrm}$. Apparently quite well after 1 week in red room, but blood calcium was 12.2. While waiting for discharge the patient developed infectious diarrhœa which proved fatal in 12 hours.

Post-mortem report. Brain congested and œdematous, no increase in fluid. Heart, 1 $1 \frac{1}{4}$ oz., slight hypertrophy of left ventricle; valves and myocardium normal. Lungs congested especially left lower lobe. Liver, 6 oz., pale and mottled. Spleen, 2 $\frac{1}{2}$ oz., looks normal. Suprarenals, very little chromaffin substance seen. Pancreas and kidneys normal. Stomach walls thin, small spots of injection seen. Several terminal intussusceptions in small intestine. Some congestion of colonic mucosa. Thyroid normal. Spinal cord appeared normal.

Sections. Brain, no inflammatory change, neuroglia a little œdematous. Spinal cord showed similar apparent increase in neuroglia cells as previous case. Heart muscle normal. Liver showed very extensive fatty infiltration and great congestion. Spleen and kidney congested but normal. Thyroid of the fotal type. Voluntary muscle normal.

G. W., female, 7 months. One month's history. Kept in ward for a fortnight, with no change in clinical condition. On October 22nd, 1932, blood calcium was 10.6. She was put into red room. By 25th she was happier, and was holding up head. By 30th she was sitting up; hands and feet were no longer pink; her limbs were firm, and she was taking feeds well. Her eyes were still running. She was taken back into ward. Eyes stopped running in four days. Discharged apparently cured 12 days from commencement of treatment. 
From these 3 cases it appears that treatment by placing the patient in light from which the rays from the violet end of the spectrum have been excluded produces rapid recovery. The unfortunate death by infective illness of 2 of them perhaps suggest that the treatment may have a bad effect on resistance, but this is so notoriously bad in pink disease that it would be unwise to draw any further conclusions, except that especial care should be taken to prevent infection in patients who are being treated by this method.

\section{Summary.}

1. Pink disease occurs in children following or during an acute infection.

2. It occurs chiefly among well cared for children in good surroundings. Twenty of the 27 cases reported came from country or suburban homes. It was first described in Australia, and has been reported from New Zealand, America, and Switzerland.

3. Only 4 of the present series of cases were admitted during the winter months.

4. The blood calcium is usually raised.

5. Erythrocytosis as well as leucocytosis is very common in this disease. There is also often an increase in the amount of hæmoglobin. The sedimentation rate may be greatly increased.

6. Intravenous or intraperitoneal injection of sodium citrate usually causes a marked temporary improvement.

7. Keeping the children in light from which the rays from the violet end of the spectrum have been filtered by means of ruby glass causes a rapid and lasting improvement in the condition. In 1 case exposure to sunlight produced symptoms of collapse.

\section{Conclusions.}

1. Pink disease is due to an abnormal reaction to daylight in an infected child. It is cured by keeping the child from daylight.

2. Further work is needed to confirm the above results, and to elucidate the problems of the blood chemistry and cytology.

My thanks are due to my house physicians for carrying out the treatment and for keeping the records, and to the entire staff of the pathological department of the Leicester Royal Infirmary for the difficult collection and examination of specimens. 


\section{REFERENCES.}

1. Swift, H., Australian Med. Cong., Children's Sect., Brisbane, 1914, 347, quoted by A. J. Wood, Med. J. Austral., Sydney, 1921, I, 145.

2. Thursfield, H., \& Paterson, D. H., Brit. J. Child. Dis., Lond., 1922, XIX, 27.

3. Paterson, D. H., \& Greenfield, J. G., Quart. J. Med., Oxford, 1923, LXV, 6.

4. Parsons, L. G., Practitioner, Lond., 1930, CXXV, 146.

5. Byfield, A. H., Am. J. Dis. Child., Chicago, 1920, XX, 347.

6. Harris, L. J., Lancet, Lond., 1932, i, 1031.

7. Hess, A. F., \& Lewis, J. M., J. Amer. Med. Ass., Chicago, 1928, XCI, 783.

8. Boas, M. A., Biochem. J., Cambridge, 1927, XXI, 712.

9. Findlay, G., \& Stern, R. O., Arch. Dis. Child., Lond., 1929, IV, 1.

10. Wyllie, W. G., \& Stern, R. O., Ibid., 1931, VI, 137.

11. Sweet, G. B., Ibid., 1930, V, 405. 